\title{
RNA isolation method for single embryo transcriptome analysis in zebrafish
}

\author{
Mark de Jong ${ }^{1}$, Han Rauwerda ${ }^{1}$, Oskar Bruning ${ }^{1}$, Jurgo Verkooijen ${ }^{1}$, Herman P Spaink ${ }^{2}$, Timo M Breit ${ }^{1 *}$
}

\begin{abstract}
Background: Transcriptome analysis during embryogenesis usually requires pooling of embryos to obtain sufficient RNA. Hence, the measured levels of gene-expression represent the average mRNA levels of pooled samples and the biological variation among individuals is confounded. This can irreversibly reduce the robustness, resolution, or expressiveness of the experiment. Therefore, we developed a robust method to isolate abundant high-quality RNA from individual embryos to perform single embryo transcriptome analyses using zebrafish as a model organism. Available methods for embryonic zebrafish RNA isolation minimally utilize ten embryos. Further downscaling of these methods to one embryo is practically not feasible.
\end{abstract}

Findings: We developed a single embryo RNA extraction method based on sample homogenization in liquid nitrogen, RNA extraction with phenol and column purification. Evaluation of this method showed that: the quality of the RNA was very good with an average RIN value of 8.3-8.9; the yield was always $\geq 200$ ng RNA per embryo; the method was applicable to all stages of zebrafish embryogenesis; the success rate was almost 100\%; and the extracted RNA performed excellent in microarray experiments in that the technical variation was much lower than the biological variation.

Conclusions: Presented is a high-quality, robust RNA isolation method. Obtaining sufficient RNA from single embryos eliminates the necessity of sample pooling and its associated drawbacks. Although our RNA isolation method has been setup for transcriptome analysis in zebrafish, it can also be used for other model systems and other applications like (q)PCR and transcriptome sequencing.

\section{Background}

Transcriptome studies of model organisms during development such as Mus musculus [1], Drosophila melanogaster [2] and Caenorhabditis elegans [3] are exciting research fields with many opportunities, yet often hampered by the availability or size of biological materials. In the last two decades Zebrafish (Danio rerio) has joined these experimental model organisms in many domains of biological and biomedical research [4-6]. This is also fueled by the convenient morpholino technique, in which antisense oligonucleotide injection -usually in eggs or embryos- effectively 'knocks down' target gene expression [7]. Additionally, the morpholino technique in combination with genome-wide transcriptome analysis has boosted developmental studies

\footnotetext{
* Correspondence: t.m.breit@uva.nl

${ }^{1}$ MicroArray Department \& Integrative Bioinformatics Unit, Swammerdam Institute for Life Sciences, Faculty of Science, University of Amsterdam, Science Park 904, 1098 XH, Amsterdam, the Netherlands
}

involving zebrafish embryogenesis. Hence, many research groups worldwide embraced this model system in their research.

In studies of genetic networks in zebrafish development [8], responses to e.g. pathogen infection $[9,10]$, or tissue specificity [11-14], biological materials are often pooled to obtain sufficient RNA. The results of these studies are undoubtedly of great value, but each measurement can only be interpreted as the average profile of the selected pool. Although pooling can be useful in some studies, the possible downsides of pooling are beyond discussion [15-17]. Pooling should therefore be an optional step, rather than a necessity. Especially with the rapidly developing zebrafish embryos that are only identified by broad-range phenotypic markers, pools of embryos will show variability because the embryos in it will not reside in the exact same embryonic phase. To tackle these drawbacks and adopt a more systems biology approach aimed at individual systems, we developed 
a reliable protocol to isolate high-quality RNA from individual zebrafish embryos with a yield sufficient for microarray analysis and other transcriptome analysis techniques.

Available methods for embryonic zebrafish RNA isolation commonly need to utilize 20 embryos or more to obtain sufficient RNA (For examples see The zebrafish book [18] and [19]). Scaling extraction volumes proportionally down to less embryos, is feasible to $\sim 10$ embryos, but smaller numbers lead to unworkable methods. One method is described to isolate RNA from 10 embryos at $36 \mathrm{hpf}(\sim 500 \mathrm{ng} /$ embryo $)$ or $52 \mathrm{hpf}$ ( $600 \mathrm{ng} /$ embryo) [13], but as these embryos were already relatively far in development, it was not clear if this would also be applicable to earlier stage embryos. In this work, several methods were investigated for isolating RNA from individual embryos with the following prerequisites: 1) Isolated RNA should display a RNA Integrity Number (RIN, quality measurement from Agilent Technologies) greater than or equal to 7.0 ; 2) The RNA yield per embryo should be sufficient to allow quality checks and downstream processing, i.e. more than $200 \mathrm{ng}$; 3) Impurities should be low, so that mRNA amplifications can be performed.

One of the challenges of isolating RNA from zebrafish is the presence of a rigid and insoluble chorion. Enzymatic degradation of the chorion is possible, but will most likely affect the transcriptome. Therefore, we chose for a sample preparation method involving mechanical disruption of the chorion under frozen conditions. RNA isolations itself, can be performed by several well-established methods based on phenol-chloroform extraction and precipitation or column-based nucleic acid purification with the aid of e.g. guanidine thiocyanate. All kinds of methods and commercial kits are available today, each with particular advantages and applications. We have tested several published methods based on phenolchloroform extractions with precipitation, column purifications and bead-based extraction methods. None of them performed well enough with respect to purity, yield and reproducibility. We therefore changed one of these methods [14] until it fulfilled our requirements of quality, yield and reproducibility. Important observations during the optimization were: 1) Incompletely homogenized samples gave lower quality RNA; 2) Good homogenization was only obtained with frozen samples; 3) Increased volumes of applied Qiazol lowered yield substantially and 4) The use of a phase-separation agent (e.g. phase-lock gel heavy) is indispensable for maximum yield and limiting Qiazol carry-over. To validate and demonstrate the value of our method, several dedicated experiments were performed.

\section{Results}

\section{RNA quality and technical variation}

To investigate the technical variation of our method, RNA was isolated from eight individual embryos (Danio rerio, strain $A B$ ) at the germ ring stage. Because embryonic staging is quite difficult, the embryos will be in a marginally different stage and will because of that, show biological variation. From four embryos, RNA was individually isolated (called Single 1 to 4 ). To eliminate the biological variation, the other four embryos were first individually homogenized, then the homogenized material was pooled, and finally split into four samples for separate RNA isolations (Semisingle 1 to 4 ). Hence, the Semi-single samples should hold the same RNA content and differences could be attributed solely to technical variation of the RNA isolation method. The quality of the isolated RNA was very good, as all RIN values were $\geq 8.3$ (Figure 1a) [Additional file 1]. All RNA isolations yielded $\geq 400 \mathrm{ng}$ (Figure 1b). As expected, the variation in RNA yield was much lower in the Semi-single samples than the Single samples. This might indicate that RNA content varies greatly between individual embryos, although column affinity differences by, for example, higher silica content could also have caused this. To further assess the quality of the isolated RNA, the mRNA from each sample was amplified, labeled, and hybridized on a custom Agilent $8 \times 15 \mathrm{k}$ zebrafish microarray using standard microarray procedures. RNA isolated from a pool of 20 embryos from the germ ring stage served as a common reference RNA sample. This RNA was isolated with similar volumes as used for single embryos as described in the methods section and yielded $\sim 350 \mathrm{ng} /$ embryo with RIN 8.7. Figure 1c shows that the mean unnormalized $\log _{2}$ signal intensities of reference, as well as test samples on all microarrays were all well-above background and highly comparable. The variance in the unnormalized $\log _{2}$ ratios (test/ reference) between the samples was investigated with a principle component analysis (PCA) (Figure 1d), which clearly showed that the 4 Semi-single samples clustered very close together, whereas the Single samples were widely spread. This implies that the technical variation of our RNA isolation method, even without data normalization, is much smaller than the biological variation, especially since most of the variance is observed on the PC1 axis (accounting for $85 \%$ of the variance). Finally, the Spearman correlation coefficients between the RNA isolations showed that the Semi-single samples are all highly similar (Figure 1e). The correlations between the reference samples were all $\geq 0.99$ (data not shown). 


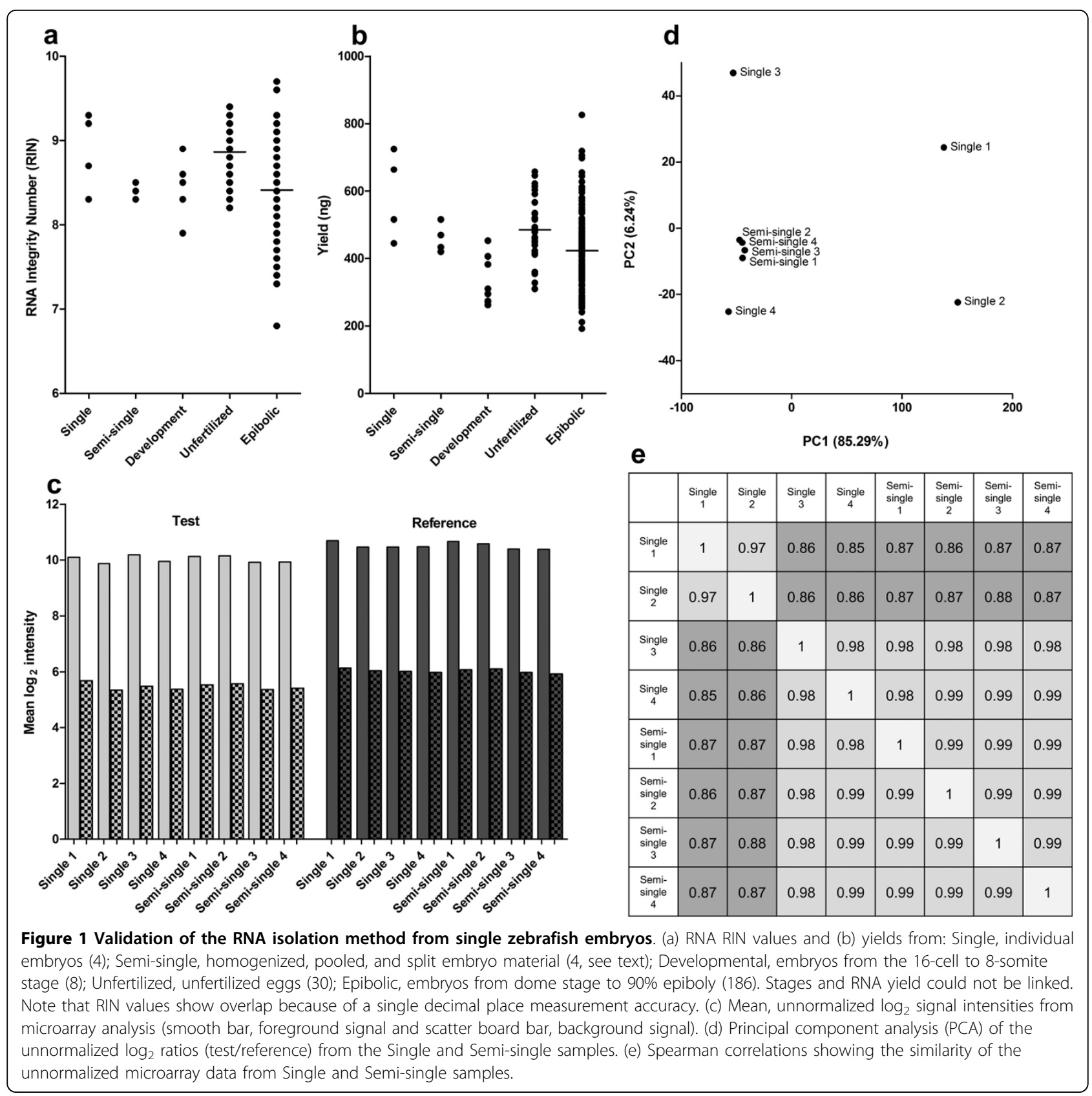

\section{Robustness}

To show the robustness of our RNA isolation methods, two experiments including larger numbers of samples were executed: 30 unfertilized eggs and 186 individual embryos, ranging from dome stage to $90 \%$ epiboly. The average RIN value of all samples was 8.9 for the unfertilized eggs and 8.4 for the epibolic samples (Figure 1a). Only one sample from all isolations was observed with a RIN value below 7.0 (Figure 1a), which is below the quality prerequisite. All samples yielded $\geq 200 \mathrm{ng}$ of RNA (Figure 1b).

\section{Applicability in zebrafish embryogenesis}

To demonstrate applicability throughout zebrafish embryogenesis, a developmental set of eight embryos was selected, ranging from 16-cell to the 8-somite stage (Figure 2a). The quality of the isolated RNA was good, as all RIN values were $\geq 7.9$ (Figure 1a) [Additional file 2] and yields were all above $200 \mathrm{ng}$ (Figure 1b). Pooling a small fraction of RNA from each sample constituted the common reference. All signals on the custom Agilent $8 \times 15 \mathrm{k}$ zebrafish microarrays were well-above background (Figure $2 \mathrm{~b}$ ) and the common reference 


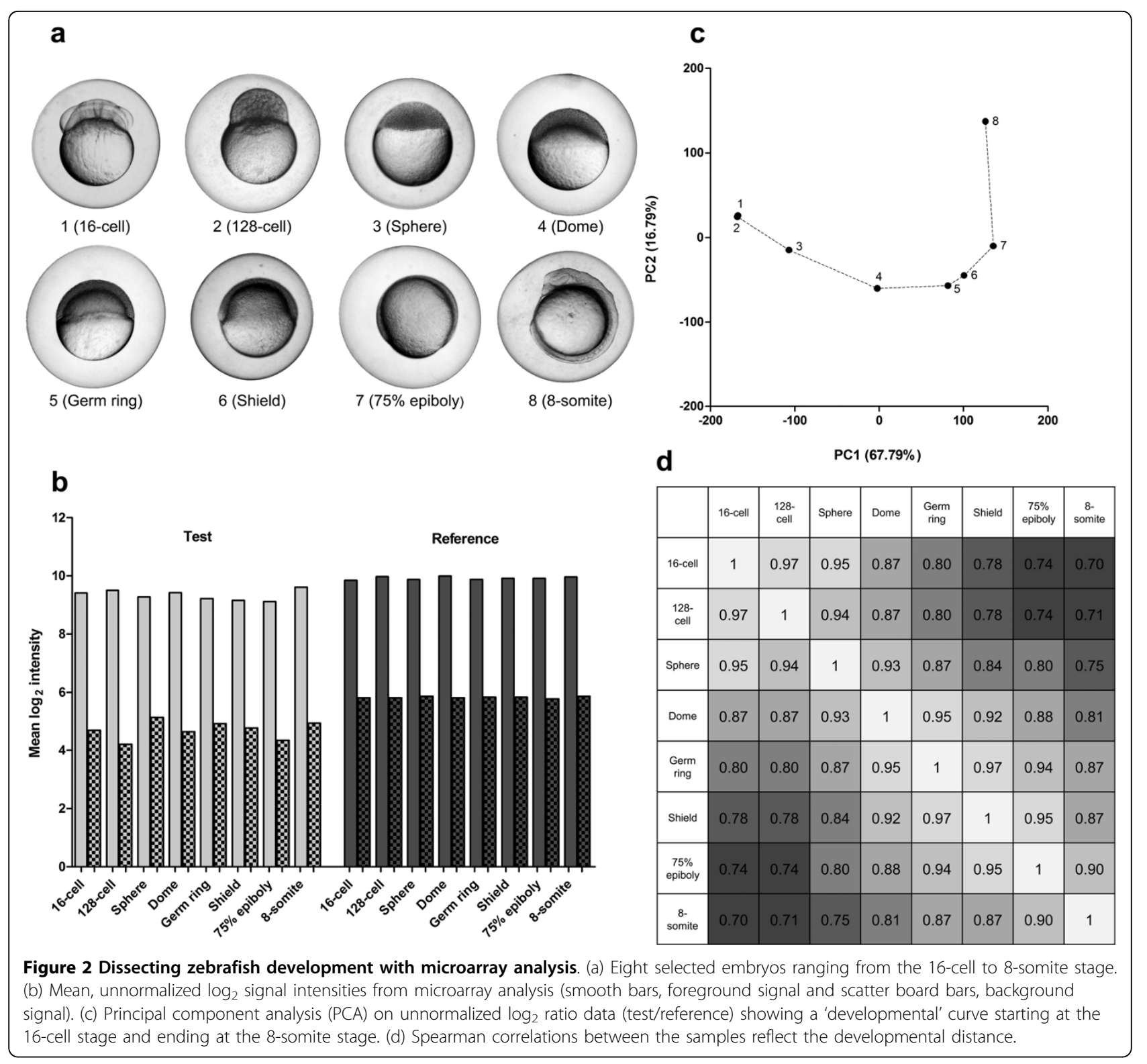

signals were highly comparable. The PCA on the unnormalized $\log _{2}$ ratios (test/reference) showed a developmentally ordered separation of all samples (Figure 2c). The Spearman correlations showed a similar picture with samples further apart in the embryogenesis having a lower correlation. The correlations between the reference samples were all $\geq 0.99$ (data not shown).

\section{Conclusions}

In summary, here we present a robust RNA isolation method for individual zebrafish embryos. The validation of this method showed that the technical variation is much lower than the biological variation. Moreover, this method seems excellently suited to distinguish different embryonic stages by microarray analysis. Although this method has been setup with a focus on transcriptome analysis, it can also be used for other applications like (q)PCR or transcriptome sequencing. Our method could also be made applicable for embryos and small samples of dissected tissues from other model systems, as we already have done for small human skin biopsies, especially when sample material is limited or pooling is unwanted.

\section{Methods}

\section{Biological materials}

Zebrafish were handled in compliance with local animal welfare regulations and maintained according to standard protocols http://zfin.org[20]. Embryos of Danio rerio (strain $A B)$ were kept at $30^{\circ} \mathrm{C}$ in egg water $(60 \mu \mathrm{g} /$ $\mathrm{ml}$ Ocean sea salts). Individual embryos were imaged 
with stereo microscopy (Leica MZ16 FA) and transferred to $1.5 \mathrm{ml}$ tubes. Remaining egg water was removed and embryos were quickly snap frozen in liquid nitrogen and stored at $-80^{\circ} \mathrm{C}$. Females were anesthetized briefly in egg water containing $0.02 \%$ buffered ethyl 3-aminobenzoate methanesulfonate (Tricaine, Sigma-Aldrich). They were transferred to petri-dishes and unfertilized eggs were harvested by gentle squeezing. Afterwards, they were allowed to recover for one month.

\section{Zebrafish test microarrays}

Microarrays have been custom designed and obtained from Agilent Technologies using the $8 \times 15 \mathrm{k}$ slide format. The $15 \mathrm{k}$ microarray (design ID: 021987) contains $\sim 15.000$ probes and has been designed on a nonrendundant set of Ensembl and Vega transcripts with a ZFIN annotation. The design for this array and microarray data discussed in this publication have been deposited in the National Center for Biotechnology Information Gene Expression Omnibus (GEO) [21-23] and are accessible through GEO series number GSE17736 and GSE17738.

\section{RNA extraction protocol}

Per RNA isolation, one $1.5 \mathrm{ml}$ tube was filled beforehand with 75-100 mg phase-lock gel heavy (5-Prime) and pelleted for $30 \mathrm{~s}$ at $12,000 \times \mathrm{g}$. Tubes with individual embryos were kept in liquid nitrogen until processing. Single embryos were grinded individually with a liquid nitrogen pre-chilled metal micro-pestle (Carl Roth). The pestle was lifted slightly and $200 \mu \mathrm{l}$ Qiazol (Qiagen) was added. The pestle was placed back into the tube with Qiazol and the homogenate was allowed to thaw. Before removal, the pestle was washed with an additional $100 \mu \mathrm{l}$ Qiazol to rinse of any material that might have stuck to the pestle. The homogenate was vortexed vigorously for $15 \mathrm{~s}$, left at room temperature for at least $5 \mathrm{~min}$, and then spun down quickly for $15 \mathrm{~s} .60 \mu \mathrm{l}$ chloroform was added to the homogenate, vortexed for $15 \mathrm{~s}$ and kept at room temperature for $3 \mathrm{~min}$. The partly separated mixture was transferred as a whole to a pre-prepared phaselock gel heavy containing tube and centrifuged for 15 $\min$ at $12,000 \times \mathrm{g}$. The aqueous phase was transferred to a new $1.5 \mathrm{ml}$ tube. The RNA was purified by column precipitation according to the RNeasy MinElute Cleanup Handbook (version 2007) - Appendix D: RNA Cleanup after Lysis and Homogenization with Qiazol Lysis Reagent (Qiagen). At the end of the procedure, the RNA was eluted in $14 \mu \mathrm{l}$ nuclease-free water.

\section{RNA yield and quality}

The amount of RNA per $\mu \mathrm{l}$ was measured on the NanoDrop ND-1000 (Thermo Scientific). The integrity of the
RNA was investigated with the BioAnalyzer (Agilent Technolgies) using the RNA pico 6000 kit (Agilent Technologies).

\section{Amplification and labelling of RNA}

200 ng RNA including controls, (Spikeset A for Cy3 and -B for Cy5, 1/16 final dilution) from the TwoColor RNA Spike-In Kit (Agilent Technologies), was taken as input for half volume reactions of the oneround mRNA amplification per zebrafish embryo (Amino-allyl MessageAmp II kit, Applied Biosystems). $5 \mu \mathrm{g}$ of amplified RNA was dried in a speedvac and dissolved in $5 \mu \mathrm{l} 50 \mathrm{mM}$ carbonate buffer ( $\mathrm{pH}$ 8.5) by thoroughly up and down pipetting and placed at $42^{\circ} \mathrm{C}$ for $5 \mathrm{~min}$. They were vortexed and spun down briefly. Vials of mono-reactive CyDyes (GE Healthcare) were dissolved in $200 \mu \mathrm{l}$ DMSO. To each reaction $10 \mu \mathrm{l}$ of dissolved CyDye was added (Test - Cy3, Reference Cy5). They were mixed thoroughly by pipetting up and down, vortexed and spun down briefly. Subsequently, samples were incubated for $60 \mathrm{~min}$ at room temperature in the dark. After 30 min the samples were vortexed and spun down briefly and left the residual 30 min in the dark. The reactions were quenched by addition of $5 \mu \mathrm{l} 4 \mathrm{M}$ hydroxylamine for $15 \mathrm{~min}$ in the dark at room temperature. $80 \mu \mathrm{l}$ of nuclease-free water was added to each sample to bring the volume to $100 \mu \mathrm{l}$. The RNA was purified with column precipitation according to the RNeasy MinElute Cleanup Handbook (version 2007) - Protocol: RNA Cleanup and Concentration (Qiagen). Finally, the RNA was eluted twice in $14 \mu \mathrm{l}$ nuclease-free water. The yield and CyDye incorporation were measured with the NanoDrop ND-1000 (Thermo Scientific).

\section{Microarray hybridization, scanning \& data processing}

Each hybridization mixture was made up from $300 \mathrm{ng}$ 'Test' and $300 \mathrm{ng}$ 'Reference' sample according to the Two-Color Microarray-Based Gene Expression Analysis Manual version 5.5 (Agilent Technologies). The RNA was allowed to hybridize for 16 hours at $65^{\circ} \mathrm{C}$ and 10 RPM. Afterwards the slides were washed and scanned in an ozone-free room with the Agilent DNA microarray scanner G2565BA (Agilent Technologies). Slides were scanned with eXtended Dynamic Range and $5 \mu \mathrm{m}$ resolution. Microarray data was extracted with Feature Extraction Software version 9.5.3 (Agilent Technologies). The obtained median signals were $\log _{2}$ converted and the average $\log _{2}$ signal intensity was calculated for the foreground and background signals. $\log _{2}$ converted ratios were used to perform standard PCA and median signal intensities were used for the calculation of Spearman correlations between samples. 
Additional file 1: RNA quality Single and Semi-single samples. This figure shows the RNA profiles of the Single and Semi-single samples as given by the Agilent 2100 BioAnalyzer together with their respective RNA Integrity Numbers (RIN).

Click here for file

[http://www.biomedcentral.com/content/supplementary/1756-0500-3-73S1.TIFF ]

Additional file 2: RNA quality Development samples. This figure shows the RNA profiles of the Development samples as given by the Agilent 2100 BioAnalyzer together with their respective RNA Integrity Numbers (RIN).

Click here for file

[http://www.biomedcentral.com/content/supplementary/1756-0500-3-73S2.TIFF ]

\section{Acknowledgements}

The authors thank the animal caretakers from Leiden University, especially $\mathrm{U}$. Nehrdich for her expertise and support.

\section{Author details}

${ }^{1}$ MicroArray Department \& Integrative Bioinformatics Unit, Swammerdam Institute for Life Sciences, Faculty of Science, University of Amsterdam, Science Park 904, 1098 XH, Amsterdam, the Netherlands. ${ }^{2}$ Department of Molecular Cell Biology, Institute of Biology, Leiden University, Gorlaeus Laboratories - Cell Observatorium, Einsteinweg 55, 2333 CE, Leiden, the Netherlands.

\section{Authors' contributions}

MdJ and TMB conceived the method and wrote the paper; MdJ developed the method; MdJ and JV performed the experiments; OB and HR analyzed the data; TMB and HPS supervised the project. All authors read and approved the final manuscript.

\section{Competing interests}

The authors declare that they have no competing interests.

Received: 5 January 2010 Accepted: 16 March 2010

Published: 16 March 2010

\section{References}

1. Hamatani T, Yamada M, Akutsu H, Kuji N, Mochimaru Y, Takano M, Toyoda M, Miyado K, Umezawa A, Yoshimura Y: What can we learn from gene expression profiling of mouse oocytes? Reproduction 2008, 135:581-592.

2. Lebo MS, Sanders LE, Sun F, Arbeitman MN: Somatic, germline and sex hierarchy regulated gene expression during Drosophila metamorphosis. BMC Genomics 2009, 10:80.

3. Capra EJ, Skrovanek SM, Kruglyak L: Comparative developmental expression profiling of two C. elegans isolates. PLoS One 2008, 3:e4055.

4. Anderson KV, Ingham PW: The transformation of the model organism: a decade of developmental genetics. Nat Genet 2003, Suppl: 285-293.

5. Ingham PW: The power of the zebrafish for disease analysis. Hum Mol Genet 2009, 18:R107-R112.

6. Brittijn SA, Duivesteijn SJ, Belmamoune M, Bertens LF, Bitter W, de Bruijn JD, Champagne DL, Cuppen E, Flik G, Vandenbroucke-Grauls CM, Janssen RA, de Jong IM, de Kloet ER, Kros A, Meijer AH, Metz JR, Sar van der AM, Schaaf MJ, Schulte-Merker S, Spaink HP, Tak PP, Verbeek FJ, Vervoordeldonk MJ, Vonk FJ, Witte F, Yuan H, Richardson MK: Zebrafish development and regeneration: new tools for biomedical research. Int J Dev Biol 2009, 53:835-850.

7. Eisen JS, Smith JC: Controlling morpholino experiments: don't stop making antisense. Development 2008, 135:1735-1743.

8. Mathavan S, Lee SGP, Mak A, Miller LD, Murthy KRK, Govindarajan KR, Tong Y, Wu YL, Lam SH, Yang H, Ruan Y, Korzh V, Gong Z, Liu ET, Lufkin T: Transcriptome Analysis of Zebrafish Embryogenesis Using Microarrays. Plos Genet 2005, 1:e29.

9. Sar Van der AM, Spaink HP, Zakrzewska A, Bitter W, Meijer AH: Specificity of the zebrafish host transcriptome response to acute and chronic mycobacterial infection and the role of innate and adaptive immune components. Mol Immunol 2009, 46:2317-2332.

10. Stockhammer OW, Zakrzewska A, Hegedûs Z, Spaink HP, Meijer AH: Transcriptome profiling and functional analyses of the zebrafish embryonic innate immune response to Salmonella infection. J Immunol 2009, 182:5641-5653.

11. Toyama R, Chen X, Jhawar N, Aamar N, Epstein J, Reany N, Alon S, Gothilf Y, Klein DC, Dawid IB: Transcriptome analysis of the zebrafish pineal gland. Dev Dyn 2009, 238:1813-1826.

12. Malek RL, Sajadi H, Abraham J, Grundy MA, Gerhard GS: The effects of temperature reduction on gene expression and oxidative stress in skeletal muscle from adult zebrafish. Comp Biochem Physiol C Toxicol Pharmacol 2004, 138:363-373.

13. Cerda GA, Hargrave M, Lewis KE: RNA profiling of FAC-sorted neurons from the developing zebrafish spinal cord. Dev Dyn 2009, 238:150-161.

14. Leung YF, Downling JE: Gene expression profiling of zebrafish embryonic retina. Zebrafish 2005, 2:269-283.

15. Mary-Huard T, Daudin JJ, Baccini M, Biggeri A, Bar-Hen A: Biases induced by pooling samples in microarray experiments. Bioinformatics 2007, 23: i313-i318.

16. Jolly RA, Goldstein KM, Wei T, Gao H, Chen P, Huang S, Colet J-M, Ryan TP, Thomas CE, Estrem ST: Pooling samples within microarray studies: a comparative analysis of rat liver transcription response to prototypical toxicants. Physiol Genomics 2005, 22:346-355.

17. Allison DB, Cui X, Page GP, Sabripour M: Microarray data analysis: from disarray to consolidation and consensus. Nat Rev Genet 2006, 7:55-65.

18. Westerfield M: The zebrafish book. A guide for the laboratory use of zebrafish (Danio rerio) Univ. of Oregon Press, Eugene, 42000.

19. Linney E, Dobbs-McAuliffe B, Sajadi H, Malek RL: Microarray gene expression profiling during the segmentation phase of zebrafish development. Comp Biochem Physiol C Toxicol Pharmacol 2004, 138:351-362.

20. The Zebrafish Model Organism Database. [http://zfin.org].

21. Gene Expression Omnibus (GEO). [http://www.ncbi.nlm.nih.gov/geo/].

22. Barrett T, Suzek TO, Troup DB, Wilhite SE, Ngau WC, Ledoux P, Rudnev D, Lash AE, Fujibuchi W, Edgar R: NCBI GEO: archive for high-throughput functional genomic data. Nucleic Acids Res 2005, 33:D562-566.

23. Edgar R, Domrachev M, Lash AE: Gene Expression Omnibus: NCBI gene expression and hybridization array data repository. Nucleic Acids Res 2002, 30:207-210.

doi:10.1186/1756-0500-3-73

Cite this article as: de Jong et al:: RNA isolation method for single embryo transcriptome analysis in zebrafish. BMC Research Notes 2010 3:73.

\section{Submit your next manuscript to BioMed Central and take full advantage of:}

- Convenient online submission

- Thorough peer review

- No space constraints or color figure charges

- Immediate publication on acceptance

- Inclusion in PubMed, CAS, Scopus and Google Scholar

- Research which is freely available for redistribution

Submit your manuscript at www.biomedcentral.com/submit
C Biomed Central 